\title{
XVIII. A new method of measuring the torsional angle of a rotating shaft or spiral spring
}

\author{
Frederick J. Jervis-Smith M.A. F.R.S.
}

To cite this article: Frederick J. Jervis-Smith M.A. F.R.S. (1898) XVIII. A new method of measuring the torsional angle of a rotating shaft or spiral spring, Philosophical Magazine Series 5, 45:273, 183-185, DOI: $10.1080 / 14786449808621120$

To link to this article: http://dx.doi.org/10.1080/14786449808621120

Published online: 08 May 2009.

Submit your article to this journal $₫$

Џ Article views: 3

Q View related articles $\square$ 
thus the energy $\frac{1}{2} m u^{2}$ communicated to the ion is equal to

$$
\frac{1}{2} \frac{\mathrm{E}^{2} d^{2} e^{2}}{\mathrm{~V}^{2}}
$$

Now the energy in the pulse is proportional to $\mathrm{E}^{2} d / \mathrm{V}^{2}$, so that the ratio of the energy communicated to the ion to the energy in the pulse is proportional to $d$. Thus the broader the pulse, the greater the absorption and the less the penetrating power. The energy in the pulse is inversely proportional to its thickness.

If we return to the expression for the intensity of the magnetic force in case (1), we see that it is proportional to $\sin \theta$, so that the disturbance is greatest at right angles to the cathode rays : thus, if the cathode particles are stopped at their first encounter, the Röntgen rays would be brightest at right angles to the cathode rays; if, however, as would seem most probable, the cathode particles had to make several encounters before they were reduced to rest, changing their direction between each encounter, the distribution of the cathode rays would be much more uniform. Experiments on the distribution of Röntgen rays produced by the impact of the cathode particles directly against the walls of the discharge-tube are, as Sir George Stokes has pointed out, affected by the much greater absorption of the oblique rays produced by the greater thickness of glass traversed by them. Experiments on rays produced by focus-tubes would give results more easily interpreted.

The result to which we have been led from the consideration of the effects produced by the sudden stoppage of an electrified particle, viz. : that the Röntgen effects are jroduced by a very thin pulse of intense electromagnetic disturbance, is in agreement with the view expressed by Sir George Stokes in the Wilde Lecture (" Proceedings of Manchester Literary and Philosophical Society,' 1897), that the Röntgen rays are not waves of very short wave-length, but impulses.

Oambridge,

Dec. 16, 1897.

XVIII. A New Method of Measuring the Torsional Angle of a Rotating Shaft or Spiral Spring. By FREDERICK J. J̈ERvisSмiтн, M.A., F.R.S., Millard and University Lecturer in Mechanics, Oxford*.

W HEN an elastic shaft is used to transmit motion, the power transmitted can be found, when the number of rotations in unit time and the torsional couple of the shaft

* Communicated by the Author. 
are known. Thus, suppose $\mathbf{E}$ to denote the $H P$ transmitted, $\mathrm{N}$ the number of rotations of the shaft per minute, the work done per minute in inch-lbs. is $12 \times 33000 \times \mathrm{E}$; and this equals the twisting moment $T$ in statical inch-lbs., multiplied by the angular motion of the shaft $2 \pi \mathrm{N}$ per minute, $i . e$.

$$
\begin{aligned}
& 2 \pi \mathrm{NT}=12 \times 33000 \times \mathrm{E}, \\
& \therefore \quad \mathrm{E}=\frac{2 \pi \mathrm{NT}}{12 \times 33000} .
\end{aligned}
$$

To find $\mathrm{E}, \mathrm{N}$ and $\mathrm{T}$ must be known. When variation in rotation is but slight, $\mathrm{N}$ may be found by means of a counter such as that of Harding, $T$ then remains to be determined. In 1894, May 2nd, the writer of this paper exhibited at the Royal Society several models of ergometers, which showed how the torsion of a rotating shaft might be measured by mechanical and optical methods, and a description was given in a pamphlet entitled "A Torsion Ergometer or WorkMeasuring Machine;" a rotostat was also exhibited, in which an inverting prism rotated in front of the index of the ergometer, brought it to rest, and made an easy reading possible although the shaft of the machine might bo making any number of revolutions per minute. The author has been subsequently informed that a similar device was used by Lord Rayleigh for blending colours. [Reprint of some Optical Papers. Lord Rayleigh, 1883.] At the time of devising the rotostat the author did not know that a rotated inverting prism had been so used for blending colours or similar purpose.

Since 1894 the problem of measuring the torsion of a very long shaft arose, the shaft being used to drive a dynamo, and also the torsion of a solenoidal spiral spring used as a flexible shaft to drive screw-propellers of different forms, in water, at different depths.

While the apparatus required is of a simple character the results obtained are sufficient and reliable.

The method is as follows (see diagram) :-Two disks of insulating material $\mathrm{A}, \mathrm{C}$ are fixed at the ends of the shaft, the bearings of which are not shown, narrow slips of copper $\mathrm{H}, \mathrm{K}$ are attached to the disks at their circumferences, and to the shaft. Two brushes D, E (single flat wires answer well), press on the edge of the disks, the brushes are connected to an electric circuit, including a battery $\mathrm{B}$, and a telephone $\mathrm{T}$. Then when $H$ and $K$ are in the same plane, at each revolution of the shaft a click is heard in the telephone; but if while the shaft is rotating the disk $\mathrm{C}$ has an angular advance on the 
disk $\mathrm{A}$, due to torsion, no click will be heard, since $\mathrm{D}$ and $\mathrm{E}$ do not touch the conductors $\mathrm{H}$ and $\mathrm{K}$ at the same instant.

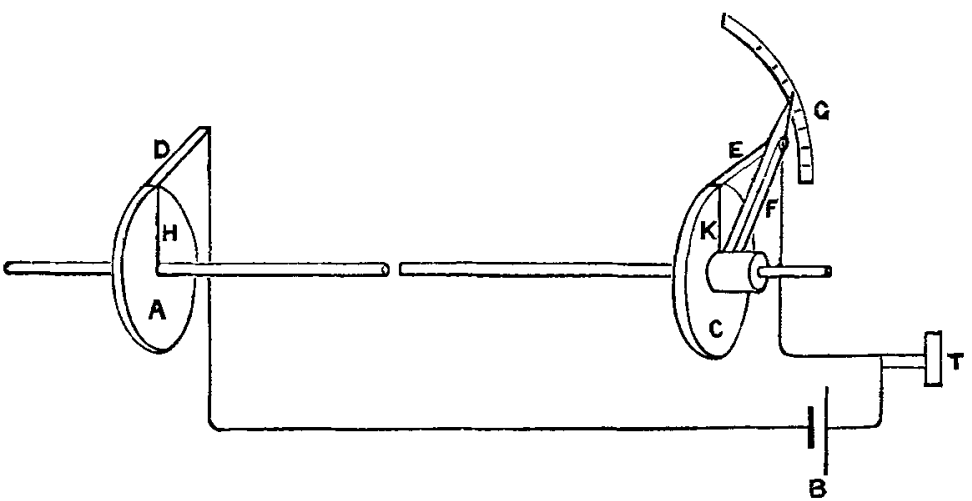

Now, in order to hear the click again, the brush-holder F must be moved through an angle equal to that of the angle of advance of $\mathrm{C}$ on $\mathrm{A}$, and this is the angle of torsion which is found. It is shown on a divided scale $G$.

The author has applied the method to find the torsional angle of an ergometer in which a solenoidal spiral spring is used instead of a shaft as shown in the figure.

The couple due to any angle is found by fixing $A$ and suspending known weights from a thin steel tape attached to a pulley of known radius keyed on to the shaft close to the disk $\mathrm{C}$.

XIX. The Source of the $\mathrm{x}$-Rays.

By John Trowbridge and John E. Burbank*.

THE experiments described in this paper were conducted with Crookes tubes containing no interval between the anode and the cathode: and no discharge, therefore, in the usual sense occurred in the tubes. $\AA$ continuous conductor was led through the rarefied tube, and it was discovered that the $x$-rays were given off from every element of this conductor at right angles to its surface when a disruptive discharge occurred in the circuit of whicl the tube formed a part. This remarkable result was obtained by means of the very high electromotive force furnished by a Planté rheostatic machine which was charged by ten thousand storage-cells. We shall describe our experiments with the various tubes we employed, and in conclusion state our results.

* Conmunicated by the Authors. 